This document is confidential and is proprietary to the American Chemical Society and its authors. Do not copy or disclose without written permission. If you have received this item in error, notify the sender and delete all copies.

\title{
Efficient resolution of racemic guaifenesin via batch preferential crystallization processes
}

\begin{tabular}{|r|l|}
\hline Journal: & Organic Process Research \& Development \\
\hline Manuscript ID & op-2019-004134 \\
\hline Danuscript Type: & Full Paper \\
\hline Author: & $25-$ Sep-2019 \\
\hline & $\begin{array}{l}\text { Complete List of Authors: } \\
\text { Temmel, Erik; Max-Planck-Institut fur Dynamik komplexer technischer } \\
\text { Seidel-Morgenstern, Andreas ; Max Planck Institute for Dynamich of } \\
\text { Complex Technical Systems; Otto von Guericke Universitat Magdeburg } \\
\text { Lorenz, Heike; Max Planck Institute for Dynamics of Complex Technical } \\
\text { Systems, }\end{array}$ \\
\hline
\end{tabular}

\section{SCHOLARONE Manuscripts}




\title{
Efficient resolution of racemic guaifenesin via batch preferential crystallization processes
}

\author{
Francesca Cascella ${ }^{1}$, Erik Temmel $^{2}$, Andreas Seidel-Morgenstern ${ }^{1,2}$, Heike Lorenz ${ }^{2}$ \\ ${ }^{1}$ Otto-von-Guericke-University Magdeburg, Chair of Chemical Process Engineering, Germany \\ ${ }^{2}$ Max Planck Institute for Dynamics of Complex Technical Systems, Germany
}

\begin{abstract}
The potential of enantioseparation processes based on preferential crystallization (PC) in single and coupled batch configuration is demonstrated for the API guaifenesin. After presenting thermodynamics and kinetics for the system guaifenesin in isopropanol, two batch crystallizationbased separation approaches are exploited. Firstly, single batch preferential crystallization in two different solvents has been studied. The results are described in terms of productivity, purity and yield with an emphasis on the role of the solvent on the enantioseparation. Secondly, we demonstrate the applicability and performance of an alternative approach, namely coupled batch preferential crystallization and selective dissolution (CPCD) for the system guaifenesin/isopropanol, and highlight advantages and drawbacks of this promising concept.
\end{abstract}

\section{INTRODUCTION}


Nowadays a large number of drugs is sold as equimolar mixture of two enantiomers. Since there are pharmacodynamic and pharmacokinetic differences between enantiomers, i.e. the desired biological activity is provided only by one, the provision of pure enantiomers has become of great interest for the pharmaceutical industries. ${ }^{[1]}$ As summarized by Lorenz et Seidel-Morgenstern, ${ }^{[2]}$ two main pathways can be followed in order to produce pure enantiomers of a chiral system. The "chiral approach" based on asymmetric synthesis of only the desired enantiomer and the "racemic approach" based on the separation of a racemic mixture, which is the $50 / 50$ mixture of both species. Among all the main strategies, preferential crystallization (PC) has the advantage of being simple and cost efficient and it is widely used for production of APIs. ${ }^{[3]}$ Promising outcomes have been reported for systems crystallizing as conglomerate, although Polenske et al. have demonstrated the possibility to extend this technique to racemic compound forming systems on the example of the mandelic acid ${ }^{[4,5]}$ In this work, the attention is focused towards an API applied against respiratory diseases that is also used as valuable precursor of muscle relaxants and tranquilizer agents. The model compound guaiacol glycerol ether, known as guaifenesin (Figure 1), belongs to the conglomerate enantiomeric system, therefore PC can be applied for its enantioseparation. ${ }^{[6]}$

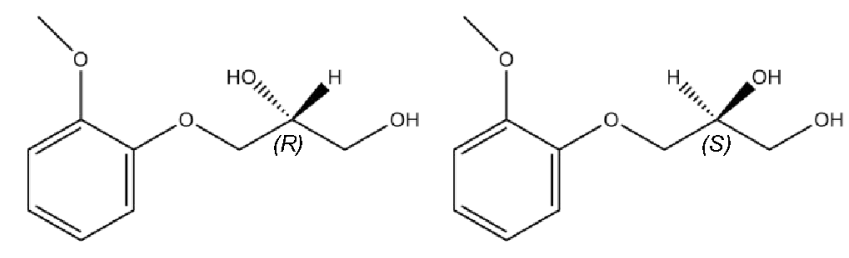

Figure 1. Molecular structure of guaifenesin enantiomers

A PC process consists in seeding a supersaturated solution of the system at racemic composition with homochiral crystals. The driving force, i.e. the supersaturation, induces growth of the initial seeds and, thus, the selective removal of only the seeded enantiomer from the liquid phase. After the crystallization of the preferred species takes place, the concentration of this component in the 
mother liquor decreases whereas the concentration of the counter-enantiomer in the liquid phase remains constant until its spontaneous nucleation occurs. In order to achieve high performance indicators (i.e. purity, productivity and yield), it is necessary to interrupt the process shortly before the antipode crystallizes. Furthermore there is no way to predict the maximum enantiomeric excess that can be reached at the end of a preferential crystallization process. ${ }^{[7]}$ As the batch operation is still the most common method utilized in pharmaceutical industry, ${ }^{[8]}$ improvements of the aforementioned limitations are needed in order to increase the robustness and to optimize the process. Much interest has been addressed towards continuous crystallization based resolutions exploiting mixed product removal (MSMPR) systems, ${ }^{[9]}$ fluidized bed crystallizers (FBC $)^{[10]}$ and several other designs of crystallizers. ${ }^{[11,12]}$ Elsner et al. ${ }^{[13]}$ have demonstrated that for the system threonine/water two opposite enantioseparations carried out in coupled configuration, outperform the single batch mode with regard to productivity and purity. In this example, the enantiomers preferentially crystallize in two vessels connected only via the liquid phase. Thus, the concentrations of both enantiomers decrease equally in both tanks and the nucleation of the counter enantiomer can be avoided over a broader supersaturation range. ${ }^{[13]}$ The same system has been resolved by means of a novel technique, a coupled preferential crystallization and dissolution (CPCD), proposed by Levilain et al. ${ }^{[14,15]}$ and exploited in the present work. The approach consists in the exchange of the crystal free liquid phase between two tanks maintained at two different temperatures. A schematic representation of the process is shown in Figure 2. 
a)

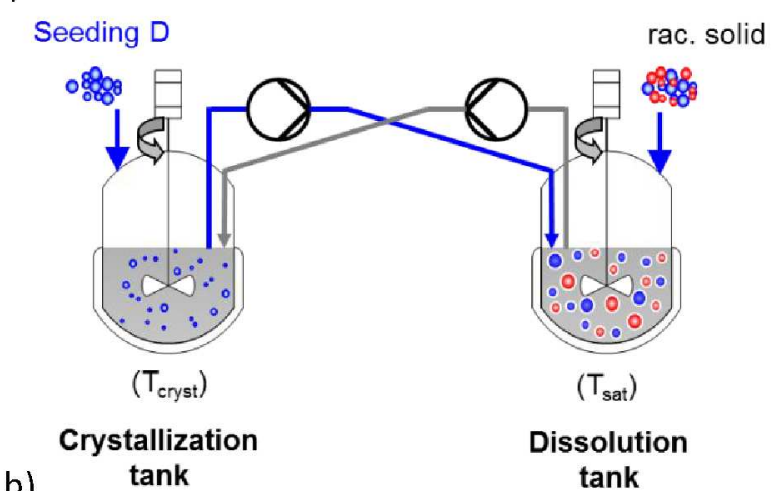

b)

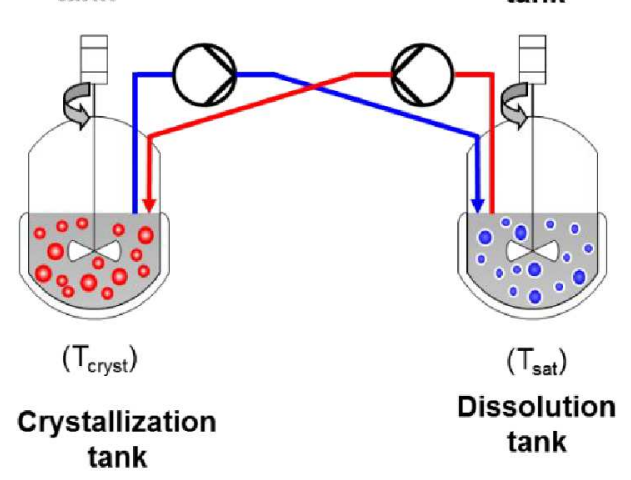

Figure 2. Principle of coupled preferential crystallization and dissolution: a) starting point and b) end of the process (adapted from ref. 16)

Initially both crystallizers are filled with a solution at racemic composition saturated at a certain temperature. Then the first tank, namely crystallization tank, is cooled to crystallization temperature and, hence, the contained solution becomes supersaturated. The second crystallizer is additionally fed with solid at racemic composition to give a certain suspension density (Figure 2a, Dissolution tank). The process starts when the supersaturated solution in the crystallization tank is seeded with homochiral crystals and the liquid exchange between the two tanks is activated. Due to growth of the seed crystals in the crystallization tank, the mother liquor is depleted with respect to the seeded enantiomer. The liquid phase is transported to the dissolution tank, which is kept at saturation temperature. Here, the liquid phase from the crystallization tank becomes undersaturated 
with respect to the seeded enantiomer and selective dissolution of this component from the excess of solid racemate takes place. If the process is not interrupted, preferential crystallization and selective dissolution proceed simultaneously until complete dissolution of the seeded enantiomer in the dissolution tank is achieved, leading to the complete resolution of the initial racemate (Figure 2b). In this context, a systematic investigation of two different batch configurations for enantioseparation of guaifenesin is performed. Single batch PC processes in two different solvents are reported and compared in terms of purity, productivity and yield. Secondly, the CPCD configuration is tested for the system guaifenesin/isopropanol. The experiments have been designed on the base of thermodynamics and kinetics of the guaifenesin/isopropanol system experimentally determined for this contribution, as well as on a previous work done by Temmel et al. ${ }^{[16]}$

\section{EXPERIMENTAL SECTION}

\subsection{Chemicals}

Racemic guaifenesin, rac-guaiacol glycerol ether, was purchased from TCI Deutschland GmbH. The purity of the substance was above $98 \%$ and was used without previous treatment. Enantiopure diol was produced before by a CPCD in water ${ }^{[14]}$ and analyzed by HPLC to confirm the purity. Millipore water from milli-Q system (merck Millipore, Milli-Q Advantage) and HPLC grade isopropanol were used for solubility measurements and crystallization experiments.

\subsection{Analytics}

HPLC analyses were performed to check the enantiomeric composition during the solubility investigations and after the crystallization runs. An Agilent 1200 system (Agilent technologies) 
equipped with a Chiralcel OD-H column $(0.46 \mathrm{~cm} \times 25 \mathrm{~cm}$, Chiral Technologies Europe, Illkirch, France) was used with the following conditions: temperature $23^{\circ} \mathrm{C}$; eluent: $35: 65$ (v/v), 2propanol/hexane; flow rate: $1.0 \mathrm{~mL}$ min-1; UV wavelength: $265 \mathrm{~nm}$.

The solid state properties of the system were investigated by XRPD analysis with an X'pert Pro Diffractometer (PANalytical $\mathrm{GmbH})$ with $\mathrm{Cu} \mathrm{K} \alpha$ radiation and an X'Celerator detector in the 2Theta range of $3-40^{\circ}$ with a step size of $0.017^{\circ}$ and a step time of $50 \mathrm{~s}$.

\subsection{Isothermal Solubility and metastable zone with (MZW) measurements}

The solubility of guaifenesin in isopropanol has been investigated by an isothermal method. Weighed amounts of guaifenesin (pure enantiomer, racemate and mixtures of both) in isopropanol together with a magnetic stir bar were filled in hermetically sealed vials of $20 \mathrm{~mL}$. The suspensions were stirred and thermostated in double-jacketed glass vessels at constant temperature. A water bath thermostat (Lauda DR.R. Wobser GmbH\&Co. KG. Deutschland) was used for heating the double-jacketed glass vessel and a Pt-100 was used for monitoring the temperature. Saturation concentrations were determined after equilibration ( $\mathrm{t}>48$ hours) by gravimetry: filtered, solidfree samples of $1 \mathrm{ml}$ were withdrawn from the suspensions, weighed and placed in a dryer in order to completely remove the solvent. The enantiomeric composition as well as a confirmation of the gravimetrically measured saturation concentration, were provided by additional HPLC analysis. The method was applied for different temperatures (between 10 and $50^{\circ} \mathrm{C}$ ) and different compositions of $(R)-/(S)$-guaifenesin in isopropanol. All measurements were repeated at least 3 times in order to estimate the interval of confidence of the solubility data. 
The preferential crystallization experiments in isopropanol have been planned based on these measurements, while the solubility in water was available in literature. ${ }^{[16]}$ Solubility data are given in terms of mass percent (eq. 1).

$$
C_{\text {sat }}(w t \%)=\frac{\text { mass solute }}{\text { mass solution }} * 100
$$

The MZW of racemic guaifenesin in isopropanol has been determined applying a polythermal method. Specific concentrations of $( \pm)$-guaifenesin in isopropanol were prepared in $6 \mathrm{~mL}$ vials. The vials, equipped with hook stirrers, were inserted in a Crystalline multiple reactor system (Technobis, The Netherlands) and heated to achieve complete dissolution. Subsequently, several cooling cycles at different cooling rates were utilized to determine the metastable zone width defined by the difference between the saturation and the nucleation temperature. The occurrence of first crystals was detected by turbidity changes and crosschecked by recorded in-line images. Data of the MZW were measured for samples with concentrations between 6.7 and $20.5 \mathrm{wt} \%$ corresponding to saturation temperatures between 20 and $40^{\circ} \mathrm{C}$. The linear cooling ramps were programmed for a temperature range of 45 to $-20^{\circ} \mathrm{C}$ with rates between $-0.5 \mathrm{~K} / \mathrm{h}$ and $-10 \mathrm{~K} / \mathrm{h}$ while the stirring speed of $400 \mathrm{rpm}$ was kept constant.

\subsection{Supersaturation calculation}

During the PC process the change of the liquid phase composition due to the selective removal of the preferred enantiomer from the mother liquor leads to an alteration of the degree of supersaturation not only of the seeded but also of the non seeded enantiomer. ${ }^{[17]}$ In this study, a comparison between two batch PC processes in two different solvents is explained, hence the variation of this alteration needs to be considered. The conventional definition of supersaturation for a binary system, expressed as the ratio between the actual concentration of the supersaturated 
solution and the saturation concentration, does not take into account the alteration of the degree of supersaturation by composition changes during the process. Therefore in the present work, the supersaturation, $\mathrm{S}(\mathrm{T})$, has been calculated considering the mass fractions of the components (eq. 2). ${ }^{[17]}$

$$
S(T)=\frac{x_{i, 0}}{x_{i, s a t}\left(T, x_{i, 0}\right)}
$$

On the base of the solubility ternary phase diagram, the reference state $x_{i, s a t}\left(T, x_{i, 0}\right)$ is given by the intersection between the extension of the solubility isotherm at crystallization temperature into the metastable zone and the extension of the tie line connecting the corner of the pure enantiomer with the composition at the actual state $\mathrm{x}_{\mathrm{i}, 0} \cdot{ }^{[17]}$

\subsection{Experimental setup}

For all the PC runs, the setup consisted of double glass jacketed tanks of $450 \mathrm{~mL}$ equipped with propeller type stirrers. The plant depicted in Figure 3 was used for both, single and coupled batch runs. 
were monitored by an on-line densitometer and on-line polarimeter respectively. In all experiments crystals of (R)-(-)-guaifenesin were used as seeds, therefore an increase of the optical rotation signal can be observed during the preferential crystallization process. For single batch PC runs (Figure 3, red dashed square), the suspension density was followed qualitatively by a turbidity probe. For the CPCD runs, the turbidity signal provides a rough quantitative information on the amount of pure enantiomer dissolved from the initial racemic excess.

\subsection{Experimental Procedures}

Single batch cooling PC runs of guaifenesin were performed in two different solvents, isopropanol and water. The experimental conditions of single batch separation runs in isopropanol and water are listed in Table 1. In order to provide a reliable comparison, the experiments have been performed under similar supersaturation.

Table 1. Experimental condition for batch PC experiments in isopropanol and water

\begin{tabular}{lll}
\hline Solvent & isopropanol & water \\
\hline supersaturation & 1.7 & 1.8 \\
$\mathrm{~T}_{\text {cryst }}\left({ }^{\circ} \mathrm{C}\right)$ & 25 & 25 \\
$\mathrm{~T}_{\text {sat }}\left({ }^{\circ} \mathrm{C}\right)$ & 36.5 & 33 \\
$\mathrm{~m}_{\text {solute }}(\mathrm{g})$ & 69.5 & 39.1 \\
$\mathrm{~m}_{\text {solvent }}(\mathrm{g})$ & 355 & 400 \\
$\mathrm{~m}_{\text {seeds }}(\mathrm{g})$ & 1.5 & 1.5 \\
\hline
\end{tabular}

The starting point of the two different PC experiments was a solution of ( \pm )-guaifenesin, saturated at $33^{\circ} \mathrm{C}$ in water and $36.5^{\circ} \mathrm{C}$ in isopropanol. The solutions were cooled to the same 
crystallization temperature $\left(\mathrm{T}_{\text {cryst }}\right), 25^{\circ} \mathrm{C}$, to create the same supersaturation given by eq. 2 . After reaching the crystallization temperature, both supersaturated solutions were seeded with $1.5 \mathrm{~g}$ of (R)-(-)-guaifenesin to initiate the process. In order to have a rough orientation of the induction time of the counter-enantiomer, hence the stop time of the experiments before spontaneous nucleation takes place, previous test runs have been performed as exemplarily shown in Figure 4. The increase of the optical rotation of the liquid phase (Figure 4, red line) as well as of the suspension density given by the turbidity signal (Figure 4, black line), shows the accumulation of the seeded enantiomer in the solid phase due to its secondary nucleation and growth. The spontaneous nucleation of the antipode, for the guaifenesin/water system, is confirmed by the optical rotation that slowly reaches a plateau 12 hours after seeding and decreases afterwards. (Figure 4b).

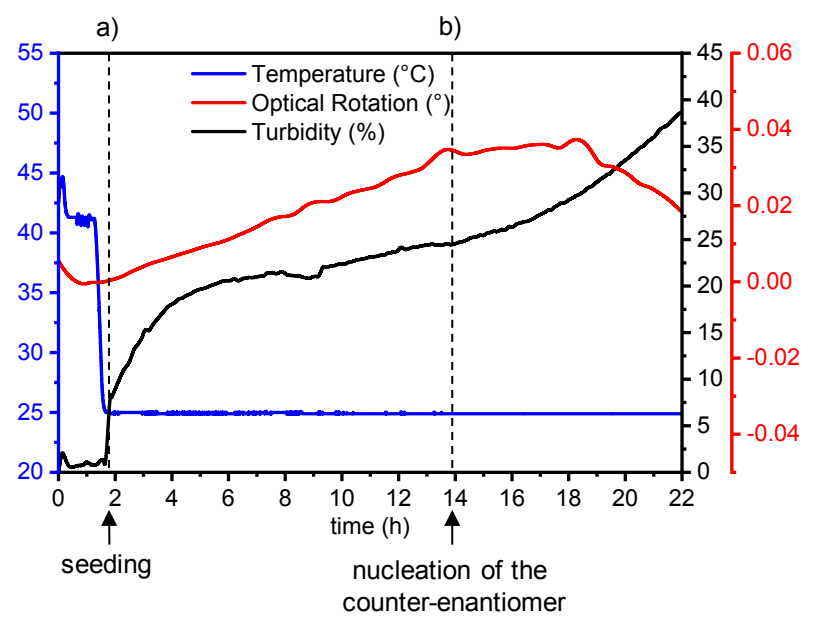

Figure 4. Process trajectories of a PC test experiment in water: the seeding a) causes a steep increase of the turbidity signal, while the nucleation of the counter-enantiomer b) causes a change of the trajectories of optical rotation and turbidity.

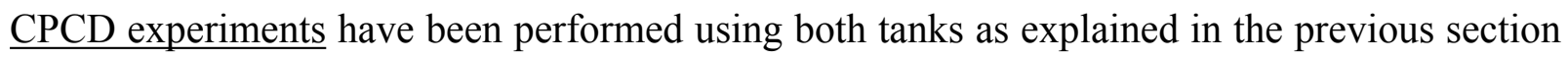
(Figure 3). Initially, both tanks were filled with a solution of ( \pm )-guaifenesin saturated at $\mathrm{T}_{\text {sat }}=35^{\circ} \mathrm{C}$ in isopropanol, heated and maintained at $45^{\circ} \mathrm{C}$ for $1 \mathrm{~h}$. The temperature of the crystallization tank 
was lowered afterwards, to $\mathrm{T}_{\text {cryst }}=25.5^{\circ} \mathrm{C}$ while the dissolution tank was cooled at saturation temperature, again $\mathrm{T}_{\text {sat, }}$ and filled with an excess of $40 \mathrm{~g}$ solid ( \pm )-guaifenesin (Table 2).

Table 2. Experimental conditions for the CPCD experiments in isopropanol.

\begin{tabular}{lll}
\hline & $\begin{array}{l}\text { Crystallization } \\
\text { tank }\end{array}$ & $\begin{array}{l}\text { Dissolution } \\
\text { tank }\end{array}$ \\
\hline $\mathrm{T}_{\text {sat }}\left({ }^{\circ} \mathrm{C}\right)$ & 35 & 35 \\
$\mathrm{~T}_{\text {cryst }}\left({ }^{\circ} \mathrm{C}\right)$ & 25.5 & 35 \\
$\mathrm{~T}_{\text {diss }}\left({ }^{\circ} \mathrm{C}\right)$ & \\
$\mathrm{m}_{\text {solute }}(\mathrm{g})$ & 40.2 & \\
$\mathrm{~m}_{\text {solvent }}(\mathrm{g})$ & 355 & 355 \\
$\mathrm{~m}_{\text {solid in excess }}(\mathrm{g})$ & & 40 \\
$\mathrm{~m}_{\text {seeds }}(\mathrm{g})$ & $1.1^{\mathrm{a}}$ & \\
\hline
\end{tabular}

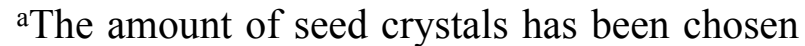
according to a previous work. ${ }^{[16]}$

The addition of $1.1 \mathrm{~g}$ of pure $(R)-(-)$-guaifenesin ( $>99.8 \%$ purity) to the supersaturated solution in the crystallization tank initiates the preferential crystallization followed by depletion of the seeded enantiomer in the liquid phase. After seeding, the exchange of the crystal free liquid phase between the two vessels was started, so that preferential crystallization and selective dissolution occur simultaneously in both tanks. The process is usually interrupted when one of the following events occurs: spontaneous nucleation of the counter-enantiomer in the crystallization tank or the complete dissolution of the seeded enantiomer in the dissolution tank. ${ }^{[14]}$ In the present study, the 
process was stopped in correspondence of the spontaneous nucleation of the counter-enantiomer, as this event occurred before the complete dissolution of the seeded enantiomer in the dissolution tank. Afterwards, the suspension collected from the vessels was filtrated and the resulting crystals were washed with ice-cold solvent.

The exchange rate plays a crucial role for counterbalancing the depletion of the preferred enantiomer from the liquid phase in the crystallization tank. The composition of the exchanged mother liquor, hence the supersaturation, is maintained at constant value. Thus, the spontaneous crystallization of the counter enantiomer can be prevented for a broad range of time. In the present study, an exchange rate of $30 \mathrm{ml} / \mathrm{min}$, which is the technical limit of this plant, appeared in test runs to be not large enough to counter balance the crystallization kinetics at the mentioned crystallization temperature, i.e. the temperature difference between the two tanks. At crystallization temperature higher that $25.5^{\circ} \mathrm{C}$, the high crystallization kinetics of the isopropanol system caused an early nucleation of the counter enantiomer in the crystallization tank, and hence, an early interruption of the process. As consequence, low purity of the product from the dissolution tank was observed in most of the experiments. On the other hand, higher crystallization temperatures increase the resolution time at the expense of the performance of the process. Therefore, only the process at $\mathrm{T}_{\text {cryst }}=25.5^{\circ} \mathrm{C}$ is reported, which best represent the potential of the CPCD configuration for the studied system.

\section{Results \\ 3.1 Solubility Measurements, solid phase characterization and MZW of the chiral system guaifenesin}


Experimental data for the solubility in isopropanol at different temperatures together with their standard deviations determined in the present study are summarized in Table 3, while the solubility of $( \pm)$-guaifenesin in water can be found in literature. ${ }^{[6,16]}$

Table 3. Solubility $\left(\mathrm{C}_{\mathrm{sat}}\right)$ and related standard deviation (SD) of racemic and enantiopure guaifenesin, at different temperatures.

\begin{tabular}{lll}
\hline \multirow{2}{*}{$\left({ }^{\circ} \mathrm{C}\right)$} & $( \pm)$-guaifenesin & $(E)^{\mathrm{b}}$-guaifenesin \\
\cline { 2 - 3 } & $\mathrm{C}_{\text {sat }}(\mathrm{wt} \%) \pm \mathrm{SD}$ & $\mathrm{C}_{\text {sat }}(\mathrm{wt} \%) \pm \mathrm{SD}$ \\
\hline 10 & $3.94 \pm 0.67$ & $2.49 \pm 0.97$ \\
20 & $6.46 \pm 0.37$ & $2.61 \pm 0.97$ \\
30 & $10.87 \pm 0.13$ & $4.99 \pm 0.95$ \\
40 & $20.49 \pm 0.31$ & $9.48 \pm 0.89$ \\
50 & $39.98 \pm 1.02$ & $20.16 \pm 0.78$ \\
\hline \multicolumn{2}{c}{ benantiopure $(R$ - or $S$-) $)$ guaifenesin }
\end{tabular}

The resulting ternary phase diagram is shown in Figure 5. The system exhibits the typical behavior of conglomerate forming systems: highest solubility at the eutectic (racemic) composition and a V-shaped form of the solubility isotherms, which are symmetric with respect to the racematesolvent line (Figure 5, black dashed line). ${ }^{[18]}$ Furthermore almost an ideal behavior of solubility with respect to the composition of the solute is observed over the studied range of temperature, i.e. the solubility lines are almost straight lines parallel to sides isopropanol- $(R)$-guaifenesin and isopropanol-(S)-guaifenesin. ${ }^{[18]}$ 


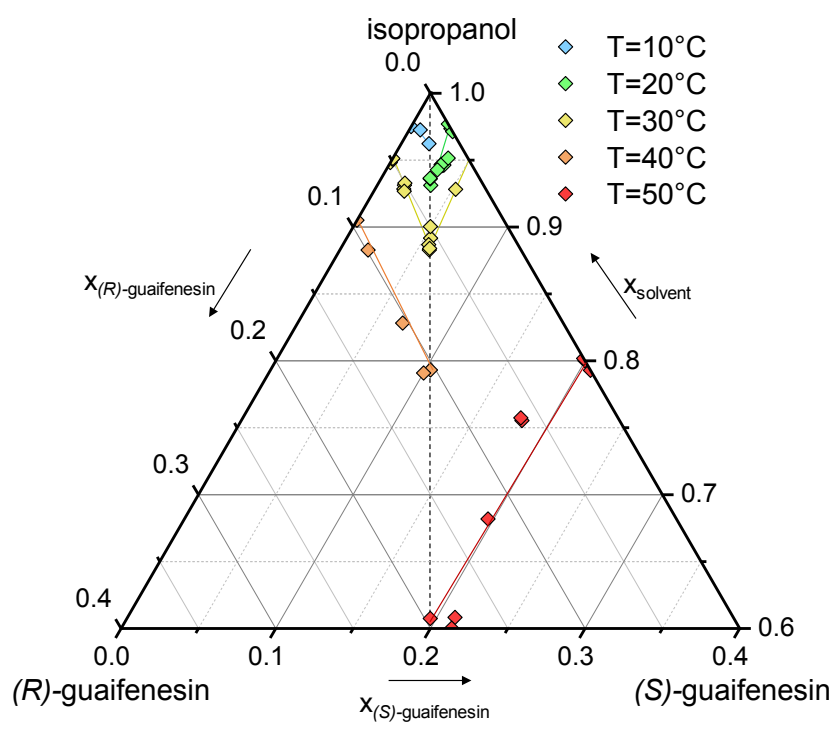

Figure 5. Ternary solubility phase diagram of guaifenesin enantiomers in isopropanol: magnification of the upper $40 \%$ section is shown. The isotherm lines are just guides to the eyes.

Figure 6 depicts the solubility of racemic guaifenesin in isopropanol as a function of temperature in comparison with the solubility of racemic guaifenesin in water.

Although the thermodynamic events that explain the solubility in the two solvents are not addressed in detail in the present work, few consideration on the experimental solubility data are worth to be mentioned. As shown in Figure 6, the strong temperature dependence of the solubility in water does not occur in isopropanol. At lower temperatures, the solubility of $( \pm)$-guaifenesin in isopropanol exceeds the corresponding data in water. Above $30^{\circ} \mathrm{C}$, while the solubility increases up to 10 times in water, it increases of a factor $<2$ in isopropanol. Two factors contribute to the high solubility of the compound in water, the solvatation by water molecules through hydrogenbond formation and the hydrophobic interaction between the non-polar portion of the drug with the water ${ }^{[19]}$ It can be assumed that, as the temperature increases, the hydrophobic interaction with the water molecules is favored not only by the decrease of the density of the water but also by the 
capability of the guaifenesin molecules to form intermolecular hydrogen bonds. ${ }^{[19,20]}$ For the isopropanol system, only the contribution of the hydrogen bonds formations can be taken in account, and hence, less temperature dependence of the solubility can be expected.

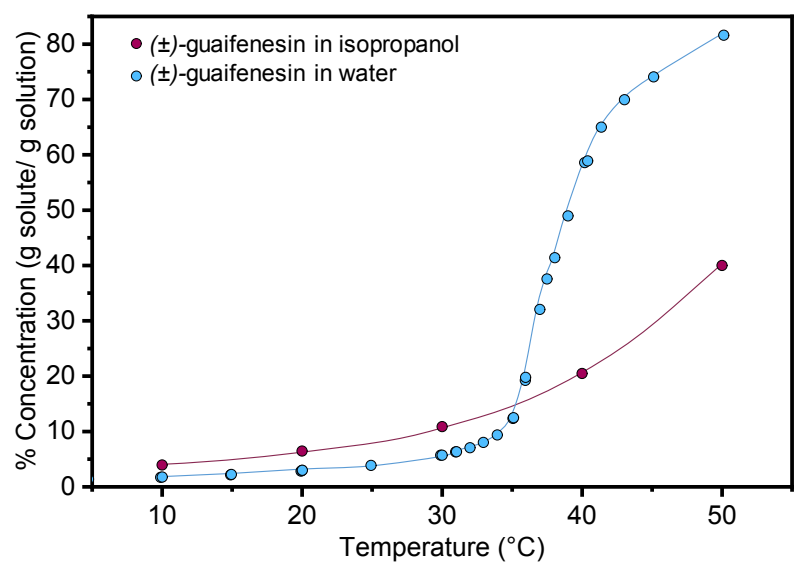

Figure 6. Solubility of $( \pm)$-guaifenesin in water (blue dots), in isopropanol (purple dots). The lines are guide to the eyes.

XRPD analysis of samples from the racemic solid phase in equilibrium with the saturated solution in isopropanol were performed in order to identify the crystalline phase as well as the formation of solvates or hydrates. As shown in Figure 7, the powder diffraction patterns of ( \pm )guaifenesin coincide with the reference pattern, confirming the presence of only one crystalline phase over the studied temperature range. 


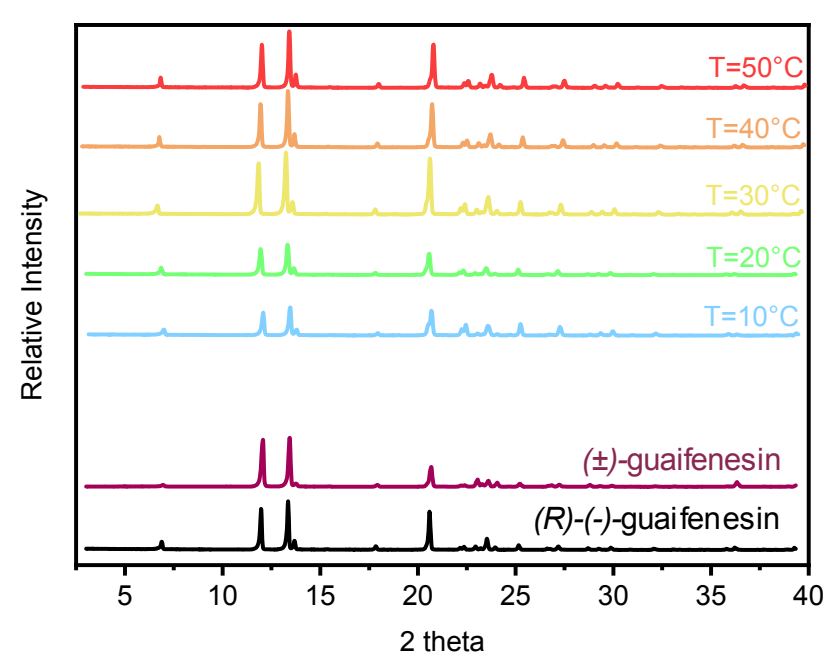

Figure 7. XRPD patterns of the solid $( \pm)$-guaifenesin in equilibrium with saturated solution between 10 and $50^{\circ} \mathrm{C}$. Reference patterns of $(R)-(-)$-guaifenesin and $( \pm)$-guaifenesin (TCI) are displayed at the bottom.

MZW has been investigated by polythermal method described in the experimental section and the related data are depicted in Figure 8.

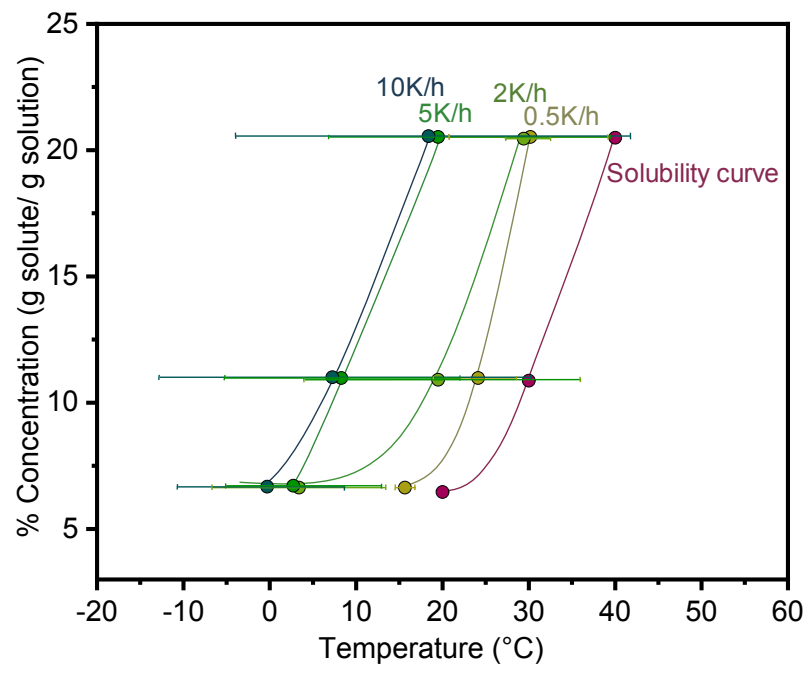

Figure 8. Nucleation temperatures of $( \pm$ )-guaifenesin/isopropanol solutions at different concentration and different cooling rates. Lines are guide to the eyes. 
The metastable zone increases with larger cooling rates as expected. The maximum subcooling with regard to primary nucleation for $( \pm)$-guaifenesin is found to be $20 \pm 9 \mathrm{~K}$ for a cooling rate of $10 \mathrm{~K} / \mathrm{h}$ and a saturation concentration of $6.5 \mathrm{wt} \%\left(\mathrm{~T}_{\mathrm{sat}}=20^{\circ} \mathrm{C}\right)$ and $22 \pm 20 \mathrm{~K}$ at saturation concentration of $20 \mathrm{wt} \%\left(\mathrm{~T}_{\mathrm{sat}}=40^{\circ} \mathrm{C}\right)$.

\subsection{Single batch PC in two different solvents}

Figure 9 shows the trajectories of the main signals during the PC runs in isopropanol (Figure 9, left) and water (Figure 9, right). The data acquisition includes as well the preparation of the supersaturated solutions in the two solvents and their equilibration, which consists in keeping the solution at $45^{\circ} \mathrm{C}$ under stirring in order to ensure complete dissolution and homogenization. The temperature profile shows the isothermal conditions of the process (Figure 9, blue line). Just after seeding with grinded crystals of pure (R)-(-)-guaifenesin, the suspension density within the crystallizer and hence the turbidity signal, increases as a results of the enrichment of the preferred enantiomer in the solid phase. As consequence, the mass fraction of the seeded enantiomer decreases in the mother-liquor, indicated by the increase of the optical rotation. 

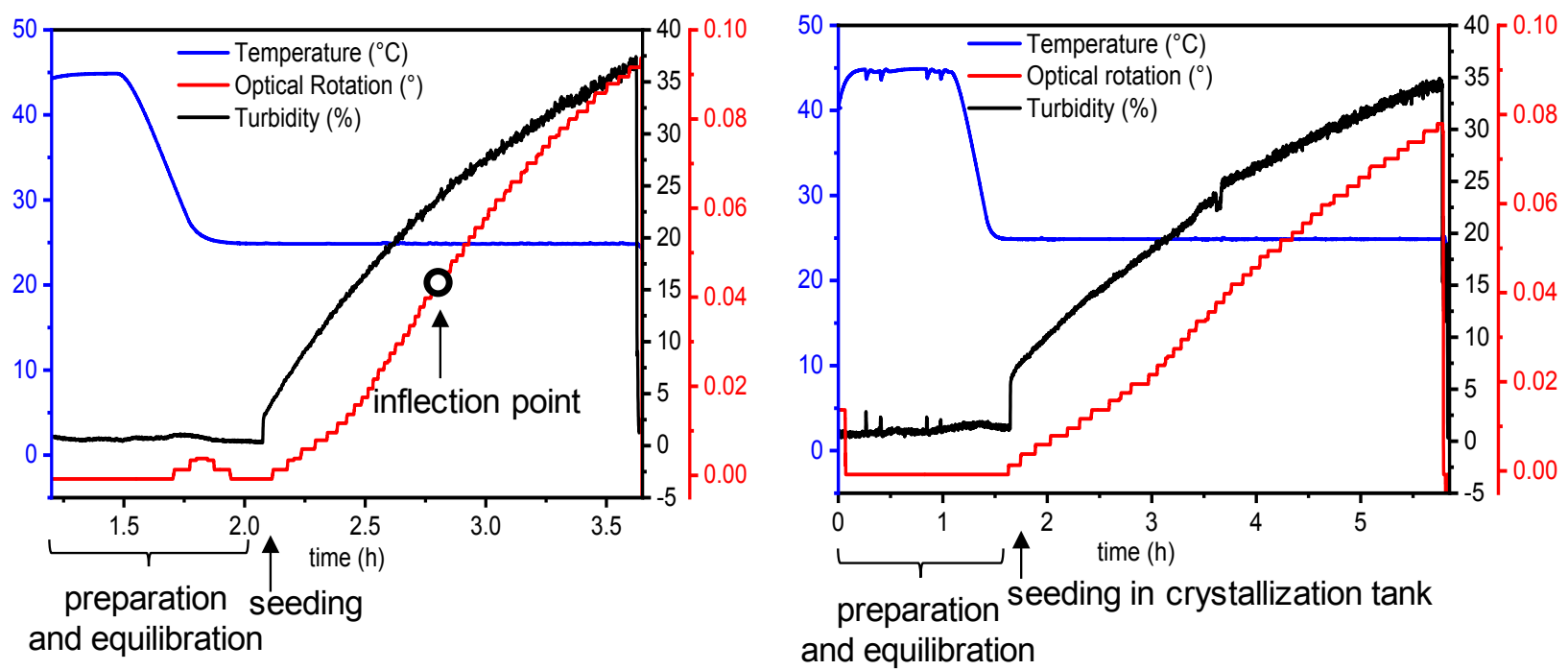

Figure 9. Evolution of process parameters during batch PC experiments in isopropanol (left) and water (right).

As expected, the solvent plays a crucial role in this separation process for a given driving force and crystallization temperature. It can be seen that the optical rotation signal as well as the turbidity signal increase faster when the process is performed in isopropanol suggesting a higher crystallization kinetics in this solvent. This behavior is confirmed by the evolution of the concentration profile during the enantioseparation processes as shown in Figure 10. After seeding, (Figure 10, $\mathrm{t}=0$ ) the concentration decay is faster for the guaifenesin/isopropanol system than for the water system as results of a faster depletion of the preferred enantiomer from the mother liquor. As already known in literature, ${ }^{[16,20]}$ the API guaifenesin exhibits slow growth kinetics in aqueous solution. Probably the interactions between the solute in the dissolved state and the water molecules, taken into account for the solubility description, slow down the process of incorporation of solute in the crystal lattice from the aqueous solution, leading to a slower crystallization kinetics for the water system. 


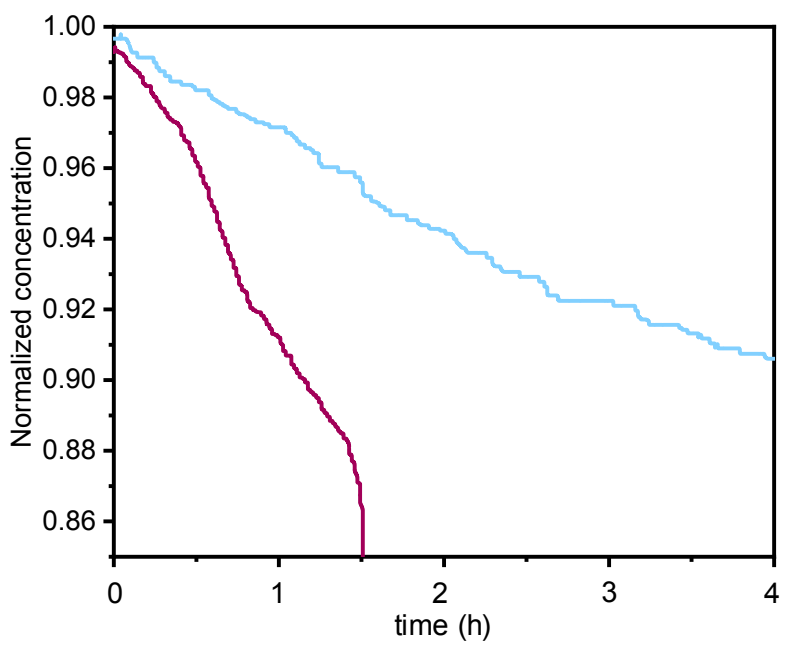

Figure 10. Depletion of the concentration after seeding from isopropanol solution (purple) and aqueous solution (blue). The concentration of the solute in the two solutions is rescaled by the saturation concentration. The seeding time was chosen as zero.

Furthermore, an inflection point of the optical rotation signal, indicating the spontaneous crystallization of the antipode, is observed for the isopropanol system (Figure 9 left, black empty dot). This event occurs after $\sim 45 \mathrm{~min}$ from the seeding in isopropanol, causing a decrease of the purity of the collected product, with respect to the water system (Table 3). Nevertheless, the decrease of the purity does not significantly affect the performance of the process in terms of productivity and yield which are corrected by the purity (eq. i and ii in Supporting Information). While the productivity increases by ten times, the yield increase by a factor $>2$ passing from water to isopropanol, indicating that with the studied conditions, the enantioseparation in isopropanol is more efficient. A further purification up to $99 \%$ of the products collected after the two processes can be easily performed according to the ternary phase diagrams of the two systems.

Table 3. Experimental results of batch PC runs in isopropanol and water. 


\begin{tabular}{lll}
\hline Solvent & isopropanol & water \\
\hline Mass product (g) & 7.55 & 3.01 \\
Time exp (h:m) & $1: 30$ & $\sim 4: 20$ \\
Purity (\%) & 96 & 98 \\
$\operatorname{Pr}(\mathrm{g} / \mathrm{h} / \mathrm{L})$ & $8.6^{\mathrm{c}}$ & $0.8^{\mathrm{c}}$ \\
$\mathrm{Y}(\%)$ & $32.6^{\mathrm{d}}$ & $13.1^{\mathrm{d}}$ \\
\hline
\end{tabular}

cd Values calculated according to eq. (i) and (ii) respectively in supporting information.

\subsection{Coupled PC and Dissolution (CPCD) in isopropanol}

As depicted in Table 4, a successful separation was performed only at $25.5^{\circ} \mathrm{C}$ as crystallization temperature in presence of $40 \mathrm{~g}$ of $( \pm)$-guaifenesin in the dissolution tank.

Figure 11 illustrates the temperature profile, as well as the trajectories of the turbidity and optical rotation signals during the CPCD run. The dashed line in Figure 11 identifies two main phases of the experiment. Before the seeding, the figure illustrates the preparation of the system consisting of the preparation of the saturated solution, its equilibration at $35^{\circ} \mathrm{C}$ and the addition of the solid in excess in the dissolution tank. Especially, the turbidity signal shows an instantaneous increase when the excess of racemic solid is added to the dissolution tank. The subsequent activation of the liquid exchange for $30 \mathrm{~min}$ ca. at constant temperature $\left(\mathrm{T}_{\text {sat }}\right.$ ), allows for equilibration of the solutions in both vessels. 

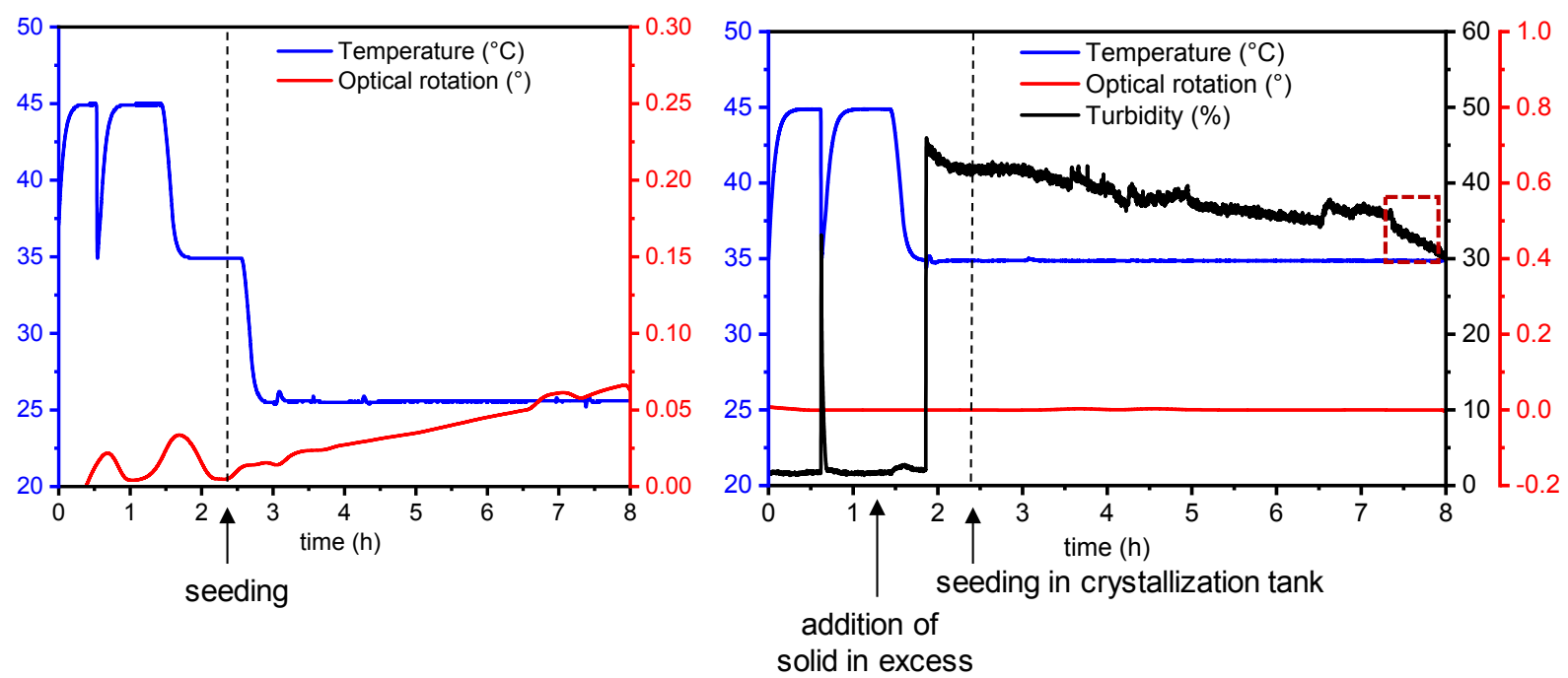

Figure 11. Evolution of process parameters in the crystallization tank (left) and in the dissolution tank (right) during a CPCD experiment.

After seeding the solution in the crystallization tank, an increase of the optical rotation is observed as result of the depletion of the seeded enantiomer from the mother liquor. However, the change of the liquid phase composition is not expected for a CPCD process. In fact, it is known as a quasi steady-state process. ${ }^{[16]}$ The fast crystallization of the seeded enantiomer in the crystallization tank, is evidently not counterbalanced by the dissolution, hence the optical rotation increases over the course of the process.

The selective dissolution of the seeded enantiomer from the solid excess in the dissolution tank can be followed by the decrease of the turbidity signal after seeding. Close to the end of the process, a faster decrease of the turbidity is observed (Figure 11, red dashed square) as consequence of a faster dissolution of the racemic excess. Such fast dissolution can be explained with the spontaneous nucleation of the counter enantiomer in the crystallization tank; as the antipode contaminates the mother liquor transported to the dissolution tank, the dissolution of both enantiomers from the solid racemic excess occurs, leading to a fast decrease of the turbidity signal. 
The process is interrupted before the turbidity signal reaches half of its initial value, indicating that not all of the enantiomer has been dissolved from the racemic solid excess in the dissolution tank, as explained in the experimental section. As consequence of the fast crystallization kinetics of the seeded enantiomer, the purities of the products collected from the crystallization tank and dissolution tank were $95 \%(\mathrm{R})$ and $80 \%(\mathrm{~S})$ respectively, as shown in Table 4 . On the other hands, although the nucleation of the counter enantiomer could not be prevented, a high yield is achieved in both tanks, $45 \%(\mathrm{R})$ and $95 \%(\mathrm{~S})$ (eq. iv and vi in supporting information). The productivity for the crystallization tank (eq. iii in supporting information) is lower in the present configuration, than the one in single tank, although the possibility to produce both enantiomers (or an enantiomerically enriched mixture), investing seeds of only one enantiomer, remains one of the strength of the process. Overall, this variant of PC outperforms the classical batch for the studied system.

Table 4. Experimental results for CPCD experiments in isopropanol.

\begin{tabular}{lll}
\hline & $\begin{array}{l}\text { Crystallization } \\
\text { tank }\end{array}$ & $\begin{array}{l}\text { Dissolution } \\
\text { tank }\end{array}$ \\
\hline mass product(g) & 18.1 & 23.7 \\
Purity (\%) & $95 \%(\mathrm{R})$ & $80 \%(\mathrm{~S})$ \\
$\operatorname{Pr}(\mathrm{g} / \mathrm{h} / \mathrm{L})$ & $7.2^{\mathrm{e}}$ & $8.4^{\mathrm{g}}$ \\
$\mathrm{Y}(\%)$ & $95 \%^{\mathrm{h}}$ \\
\hline $\begin{array}{l}\text { efgh Values calculated according to eq. (iii) (iv) (v) } \\
\text { (vi) respectively in supporting information. }\end{array}$
\end{tabular}




\section{CONCLUSIONS}

A systematic investigation of two different configurations of crystallization based separation processes has been presented. Isothermal solubility measurements, MZW and solid state properties of the system guaifenesin/isopropanol indicated the possibility to preferentially crystallize enantiomers of the API from its saturated solution in isopropanol. Single batch preferential crystallization is thus performed and compared, in terms of performance indicators, with the counterpart in water. Although a similar driving force was ensured for the two systems, the results highlight the role of the solvent on the crystallization kinetics. Higher productivity and yield were achieved with the separation from isopropanol in comparison with the water system. The applicability of a different configuration, consisting in coupled preferential crystallization and selective dissolution for the system guaifenesin/isopropanol, has been investigated. The process was carried out in two vessels coupled via liquid phase. The higher crystallization kinetic observed in isopropanol, caused a fast depletion of the preferred enantiomer from the mother liquor. As consequence, the exchange rate between the two tanks resulted not sufficient to counterbalance the preferential crystallization of the preferred enantiomer with its selective dissolution in the dissolution tank, leading to a non-optimal separation. The results of experimental runs here presented show the limitation of the utilized plant for fast crystallizing systems, suggesting that future improvements of the configuration could be done, besides striving for a better understanding of the kinetics of the studied chiral system. 


\section{ASSOCIATED CONTENT}

\section{Supporting Information}

Equations used for calculation of yield and productivity for single batch PC processes

$$
\begin{aligned}
& \operatorname{Pr}=\frac{\left(\mathrm{m}_{\mathrm{pr}} * \mathrm{Pu}\right)-\mathrm{m}_{\text {seed }}}{\mathrm{V}_{\text {cryst }} * \mathrm{t}_{\text {exp }}} \\
& \mathrm{Y}=\frac{\left(\mathrm{m}_{\mathrm{pr}} * \mathrm{Pu}\right)-\mathrm{m}_{\text {seed }}}{\mathrm{m}_{\text {theo }} * 0.5}
\end{aligned}
$$

Equation used for calculation of yield and productivity for CPCD process

Crystallization tank

$$
\begin{aligned}
& \operatorname{Pr}=\frac{\left(\mathrm{m}_{\mathrm{pr}} * \mathrm{Pu}\right)-\mathrm{m}_{\text {seed }}}{\mathrm{V}_{\text {cryst }} * \mathrm{t}_{\text {exp }}} \\
& \mathrm{Y}=\frac{\left(\mathrm{m}_{\mathrm{pr}} * \mathrm{Pu}\right)-\mathrm{m}_{\text {seed }}}{\left(\mathrm{m}_{\text {theo }} * 0.5\right)+\left(\mathrm{m}_{\text {solid excess }} * 0.5\right)}
\end{aligned}
$$

Dissolution tank

$$
\begin{gathered}
\mathrm{Pr}=\frac{\left(\mathrm{m}_{\mathrm{pr}} * \mathrm{Pu}\right)}{\mathrm{V}_{\text {cryst }} * \mathrm{t}_{\exp }} \\
\mathrm{Y}=\frac{\left(\mathrm{m}_{\mathrm{pr}} * \mathrm{Pu}\right)}{\mathrm{m}_{\text {solid excess }} * 0.5}
\end{gathered}
$$

\section{AUTHOR INFORMATION}

Corresponding Author

*E-mail: cascella@mpi-magdeburg.mpg.de 


\title{
Funding Sources
}

This research received funding as part of a CORE project (October 2016-September 2020) from the Horizon2020 Research and Innovation Programme of the European Union under Marie Sklodowska-Curie Grant Agreement No. 722456CORE ITN.

\section{ACKNOWLEDGEMENT}

The authors thank Jonathan Gänsch (Max Planck Institute, Magdeburg) for fruitful discussions.

\begin{abstract}
ABBREVIATION
API, active pharmaceutical ingredient; PC, preferential crystallization; CPCD, coupled preferential crystallization and dissolution; MZW, metastable zone width; S, supersaturation.
\end{abstract}




\section{REFERENCES}

[1] Nguyen, L. A.; Chuong Pham-Huy, H. H. Chiral Drugs: An Overview. Int J Biomed Sci. 2006, 2(2), 85-100.

[2] Lorenz, H.; Seidel-Morgenstern, A. Processes To Separate Enantiomers. Angew. Chem. Int. Ed. 2014, 53, 1218-1250.

[3] Wang, Y.; Chen, A. M. Enantioenrichment by crystallization. Org. Process Res. Dev. 2008, $12(2), 282-290$.

[4] Coquerel, G. Preferential Crystallization. In Novel Optical Resolution Technologies; Sakai, K., Hirayama, N., Tamura, R.; Springer: Berlin, Heidelberg, 2006, pp 19-41.

[5] Polenske, D.; Lorenz, H.; Seidel-Morgenstern, A. Potential of different techniques of preferential crystallization for enantioseparation of racemic compound forming systems. Chirality, 2009, 21, 728-737.

[6] Fayzullin, R.; Lorenz, H.; Bredikhina, Z., A.; Bredikhin, A. A.; Seidel-Morgenstern, A. Solubility and Some Crystallization Properties of Conglomerate Forming Chiral Drug Guaifenesin in Water. Journal of Pharmaceutical Sciences, 2014, 103, 3176-3182.

[7] Levilain, G.; Coquerel, G. Pitfalls and rewards of preferential crystallization. CrystEngComm. 2010, 12, 1983-1992.

[8] Li, J.; B., L., Trout; Myerson, A., S.; Multistage Continuous Mixed-Suspension, MixedProduct Removal (MSMPR) Crystallization with Solids Recycle. Org. Process Res. Dev. 2016, 20(2), 510-516. 
[9] Galan, K.; Eicke, M., J.; Elsner, M., P.; Lorenz, H.; Seidel-Morgenstern, A. Continuous Preferential Crystallization of Chiral Molecules in Single and Coupled Mixed-Suspension MixedProduct-Removal Crystallizers. Cryst. Growth Des. 2015, 15(4), 1808-1818.

[10] Binev, D.; Seidel-Morgenstern, A.; Lorenz, H. Continuous Separation of Isomers in Fluidized Bed Crystallizers. Cryst. Growth Des. 2016, 13(3), 1409-1419.

[11] Wood, B.; Girard, K., P.; Polster, C., S.; Crocker, D. Progress to Date in the Design and Operation of Continuous Crystallization Process for Pharmaceutical Applications. Org. Process Res. Dev. 2019, 23, 122-144.

[12] Rougeot, C.; Hein, J., E. Application of Continuous Preferential Crystallization to Efficiently Access Enantiopure Chemicals. Org. Process Res. Dev. 2015, 19, 1809-1819.

[13] Elsner, M. P.; Ziomek, G.; Seidel-Morgenstern, A. Efficient Separation of Enantiomers by Preferential Crystallization in Two Coupled Vessels. AIChE Journal, 2009, 55(3), 640-649.

[14] Levilain, G.; Eicke, M. J.; Seidel-Morgenstern, A. Efficient Resolution of Enantiomers by Coupling Preferential Crystallization and Dissolution. Part 1: Experimental Proof of Principle. Cryst Growth Des. 2012, 12(11), 5396-5401.

[15] Eicke, M. J.; Levilain, G.; Seidel-Morgenstern, A. Efficient Resolution of Enantiomers by Coupling Preferential Crystallization and Dissolution. Part 2: A Parametric Simulation Study to Identify Suitable Process Conditions. Cryst Growth Des. 2013, 13(4), 1638-1648.

[16] Temmel, E.; Eicke, M., Cascella, F. J.; Seidel-Morgenstern, A.; Lorenz H. Resolution of racemic guaifenesin applying a coupled preferential crystallization-selective dissolution processRational process development, Cryst Growth Des. 2019, 19, 3148-3157. 
[17] Temmel, E.; Gänsch, J.; Lorenz, H.; Seidel-Morgenstern, A. Measurements and evaluation of the crystallization kinetics of L-asparagine monohydrate in the ternary L-/D-asparagine/water system. Cryst Growth Des. 2018, 18(12), 7504-7517.

[18] Jacques, J.; Collet, A.; Wilen, S.H. Enantiomers Racemates and Resolution; Krieger Publishing Company, Malbar, FL, 1981.

[19] Mani, N.; Jun, H. W.; Warren Beach, J.; Nerurkar, J. Solubility of Guaifenesin in the Presence of Common Pharmaceutical Additives. Pharmaceutical development and technology. 2003, 8(4), 385-396.

[20] Kaduk, A. J. Crystal structure of guaifenesin, 3-2-methoxyphenoxy-1,2-propanediol. Powder Diffraction. 2004, 19 (2), 127-132. 


\section{For table of content use only}

\section{Title}

Efficient resolution of racemic guaifenesin via batch preferential crystallization processes

\section{Authors}

Francesca Cascella, Erik Temmel, Andreas Seidel-Morgenstern, Heike Lorenz

\section{TOC}

Pure enantiomers of the API guaifenesin are produced via Preferential Crystallization (PC), exploiting two batch configurations. A comparison of the processes in terms of performance indicators highlights the role of the solvent on the enantioseparation in a single vessel. The alternative Coupled Preferential Crystallization and Dissolution is applied and its performance parameters are discussed for the studied system, providing a useful guideline for further applications.

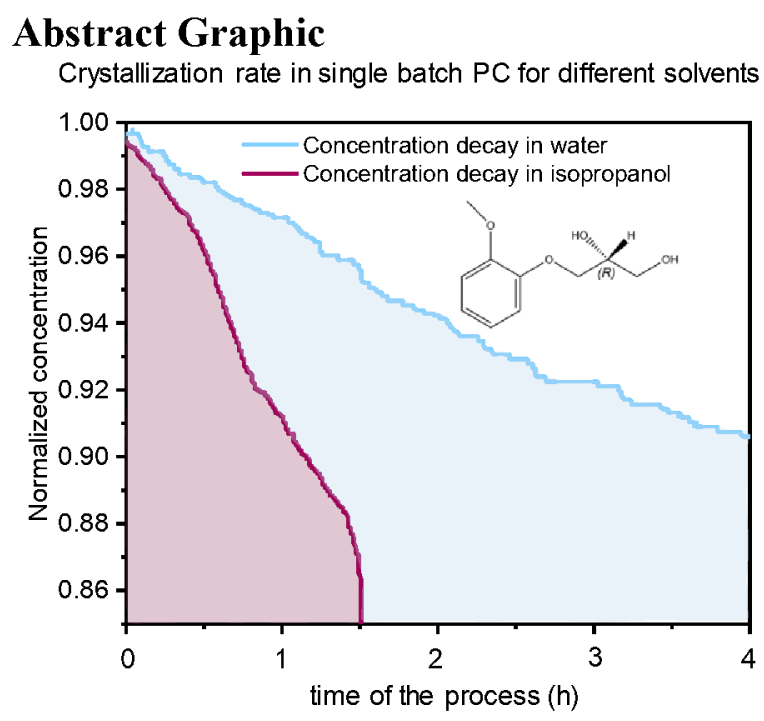

